\title{
A giant periosteal chondroma of the distal femur successfully reconstructed with synthetic bone grafts and a bioresorbable plate: a case report
}

Yoshinori Imura ${ }^{1}$, Atsuo Shigi ${ }^{1}$, Hidetatsu Outani ${ }^{1}$, Kenichiro Hamada ${ }^{1}$, Hiromi Tamura ${ }^{2}$, Eiichi Morii ${ }^{2}$, Akira Myoui ${ }^{1}$, Hideki Yoshikawa ${ }^{1}$ and Norifumi Naka ${ }^{1 *}$

\begin{abstract}
Periosteal chondromas are rare benign cartilaginous tumors that arise adjacent to the cortex beneath the periosteum. These lesions are usually slow-growing and rarely exceed $3 \mathrm{~cm}$ in the greatest dimension. Here, we describe a 17-year-old boy who had a giant periosteal chondroma of the right distal femur, which was treated with intralesional resection and intensive curettage. In addition, we report a novel application of a bioresorbable plate in the management of the large bone defect after resection of a benign bone tumor.
\end{abstract}

Keywords: bioresorbable plate, distal femur, intensive curettage, intralesional resection, periosteal chondroma, synthetic bone grafts

\section{Background}

Periosteal chondromas (juxtacortical chondromas) were first described by Lichtenstein and Hall in 1952 [1]. They are relatively uncommon, benign, hyaline cartilage tumors that account for less than $2 \%$ of chondromas and are generally seen in men in their second and third decades of life [2-6]. These lesions develop adjacent to the cortical surface of bone beneath the periosteal membrane and often arise at the metaphyses of long tubular bones, most commonly the humerus followed by the femur and tibia [3-6]. They are slow-growing tumors and usually smaller than $3 \mathrm{~cm}[7,8]$.

Here, we report a case of a giant periosteal chondroma involving the right distal femur in a 17 -year-old boy. We treated this patient by intralesional resection and intensive curettage, resulting in a large bone defect. We successfully performed reconstruction of the defect using interconnected porous calcium hydroxyapatite (IP-CHA) and a bioresorbable plate.

\section{Case presentation}

A 17-year-old boy presented to our hospital with mild pain in his right thigh, which he had experienced for the

\footnotetext{
* Correspondence: nnaka@ort.med.osaka-u.ac.jp

'Department of Orthopaedic Surgery, Osaka University Graduate School of

Medicine, 2-2 Yamadaoka, Suita, Osaka 565-0871, Japan

Full list of author information is available at the end of the article
}

previous month. The patient stated that 6 years earlier he had hit this same thigh and felt pain and swelling at that time. Then he visited the local doctor and a mass on the anterior surface of his right distal femur was revealed by plain radiographs. The symptoms gradually decreased with time and he had received a follow-up examination from the doctor. The patient had an otherwise unremarkable past medical history.

At the first presentation to our clinic, physical examination revealed a firm, nontender mass with ill-defined margins at the anterior aspect of his right thigh. The mass was neither freely moveable nor adherent to the skin. Range of motion was decreased at the right knee joint. Plain radiographs showed that the lesion was located on the anterior surface of the right distal femur with cortical erosion, saucerization of the underlying cortex, and a rim of sclerosis (Figure 1a,b). In addition, computed tomography (CT) showed an extraskeletal mass with focal calcification (Figure 2a,b). Magnetic resonance imaging (MRI) showed low intensity in the T1weighted image and high intensity in the T2-weighted image (Figure 3a-d). The mass measured $8.9 \mathrm{~cm}$ long by $2.7 \mathrm{~cm}$ wide with a maximum height of $3.1 \mathrm{~cm}$. The mass did not appear to invade the intramedullary canal. A preoperative diagnosis of periosteal chondroma or lowgrade (grade 1) periosteal chondrosarcoma was made. As 

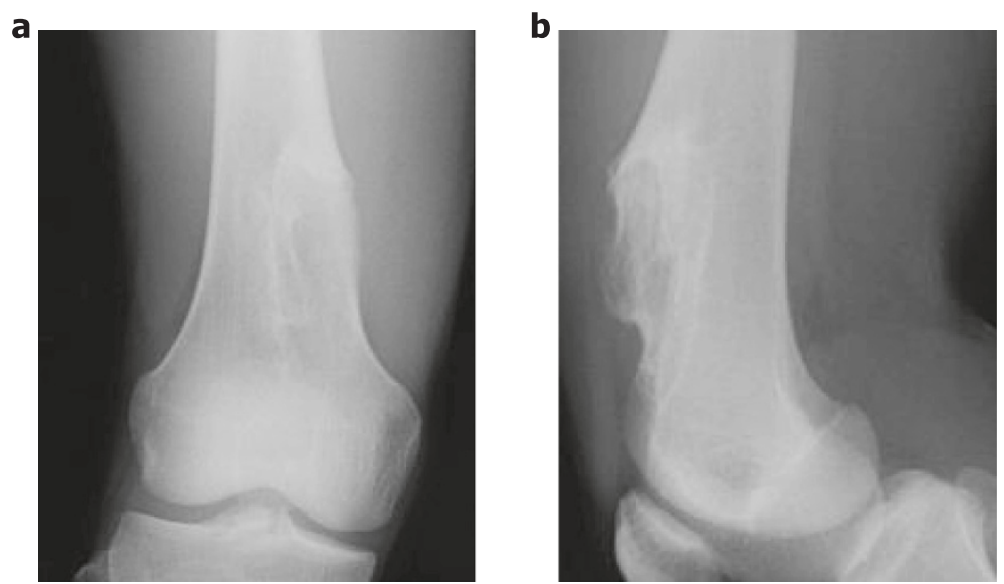

Figure 1 Preoperative plain radiographs. (a) Anteroposterior and (b) lateral radiographs showing cortical erosion, saucerization of the underlying cortex, and a rim of sclerosis on the anterior surface of the right distal femur.

both of these tumors are frequently less aggressive than high-grade (grade 2 or 3 ) chondrosarcomas, we elected to perform intralesional resection and intensive curettage after intraoperative pathological consultation instead of biopsy.

We operated according to the preoperative surgical plan. The tumor was well-circumscribed without invasion into the muscle or subcutaneous tissue (Figure 4a). Macroscopically, the periosteal tumor consisted of an oval, well-circumscribed, cartilaginous tumor, measuring $9 \times 3 \times 3 \mathrm{~cm}$ in greater dimension (Figure $4 \mathrm{~b}$ ). An intraoperative rapid pathological diagnosis of periosteal chondroma or low-grade periosteal chondrosarcoma was made. After resection and intensive curettage of the entire lesion, we noted a large bone defect of the anterior aspect of the distal femur (Figure 4c). We then grafted IP-CHA (Neobone ${ }^{\circ}$; MMT Co. Ltd., Osaka, Japan) [9] to the defect and covered it with a bioresorbable plate (Super FIXSORB ${ }^{\circ}$ MX Mesh; Takiron Co. Ltd., Osaka, Japan) (Figure 4d). Histological examination of the resected specimen showed a hyaline cartilage tumor arranged in a lobular pattern and covered by periosteum without cytologic atypia or mitosis (Figure 5a,b). The margins of the mass were circumscribed, with no evidence of invasion or permeation of adjacent structures. The final pathological diagnosis was periosteal chondroma. a

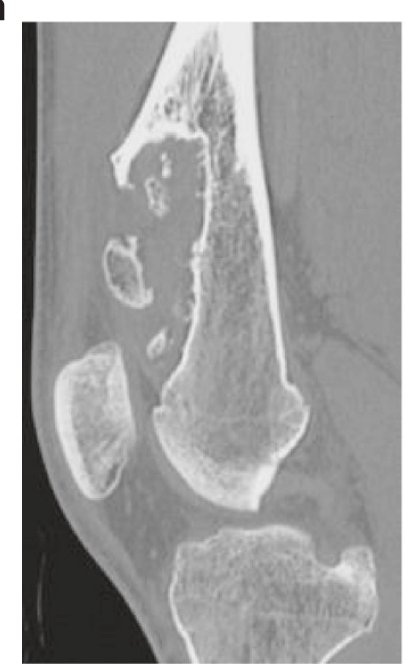

b

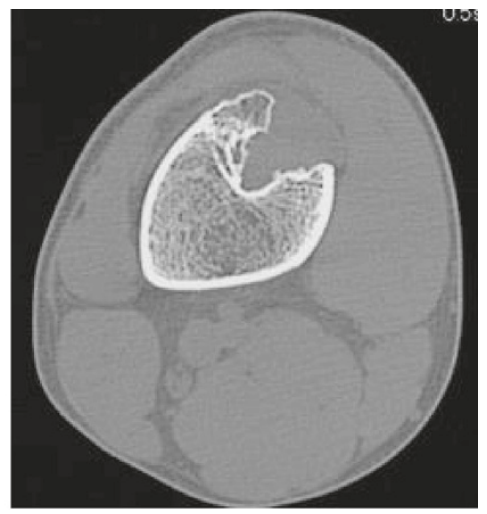

Figure 2 Preoperative CT. (a) Sagittal and (b) axial scans, showing an extraskeletal mass with focal calcification on the anterior surface of the right distal femur. 


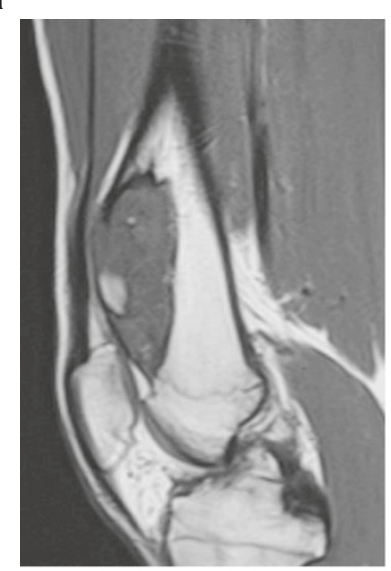

C

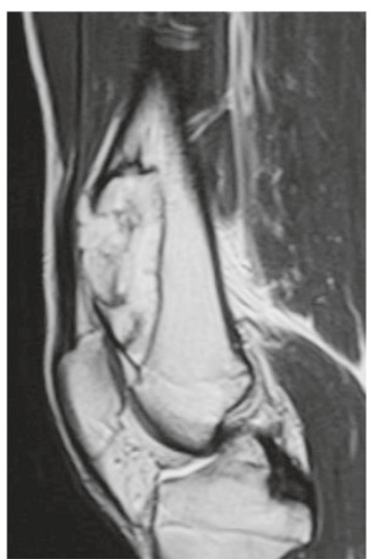

b

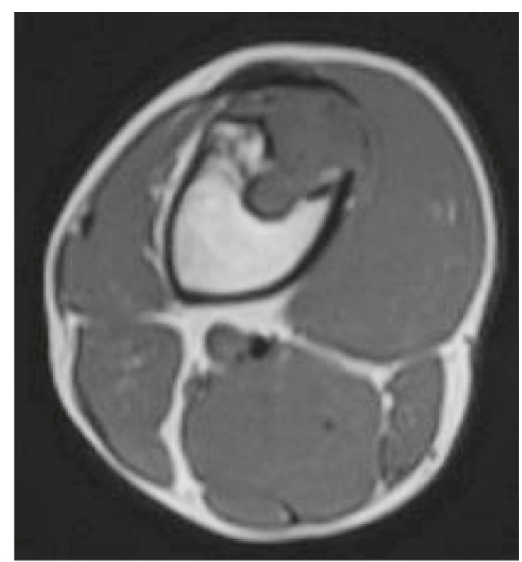

d

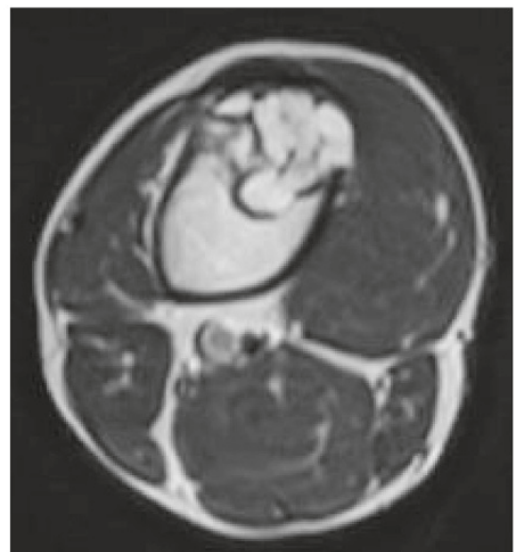

Figure 3 Preoperative MRI. (a) Sagittal and (b) axial T1-weighted images, showing a low-intensity mass on the anterior surface of the right distal femur. (c) Sagittal and (d) axial T2-weighted images, showing a high-intensity mass. No evidence of marrow invasion was seen.

The patient's postoperative course was uneventful and he was discharged on postoperative day 14. Six months after surgery, the range of motion in his right knee was fully recovered and he returned to sports, including football and baseball. Final radiographs revealed that particles of IP-CHA were almost consolidated after the operation (Figure 6a-d). There has been no sign of local recurrence during the 12 months since the surgical resection.

\section{Discussion}

Benign and malignant periosteal chondroid tumors are now recognized as distinct disease entities. The differential diagnosis to distinguish between periosteal chondromas and periosteal chondrosarcomas is necessary for avoiding aggressive and inappropriate treatment. There are three fundamental radiographic features of periosteal chondromas, including scalloping or remodeling of the adjacent bony cortex, the presence of cartilaginous matrix that appears as small dots and ringlets of calcification, and a possible soft tissue mass component
$[8,10,11]$. Although scalloping and sclerosis of the cortex can be similar in the two lesions, periosteal chondrosarcomas tend to invade the underlying bone, form no reactive bone underlying the cortical lesion, and present a large mass in the soft tissue [12]. In this case, imaging features of the tumor were characteristic of a periosteal chondroma but not of a periosteal chondrosarcoma.

It has been reported that the median size of periosteal chondrosarcomas was considerably larger than that of chondromas $[7,8]$. In this case, the size of the tumor was approximately $9 \mathrm{~cm}$ in the longest diameter but had taking more than 6 years to grow to this size, suggesting that the tumor might be a giant periosteal chondroma rather than a slow-growing low-grade periosteal chondrosarcoma. In fact, the final pathological diagnosis was periosteal chondroma.

Nevertheless, it is frequently difficult to differentiate periosteal chondromas from low-grade periosteal chondrosarcomas. Wide excision is the treatment of choice in high-grade chondrosarcomas but may result in increased 

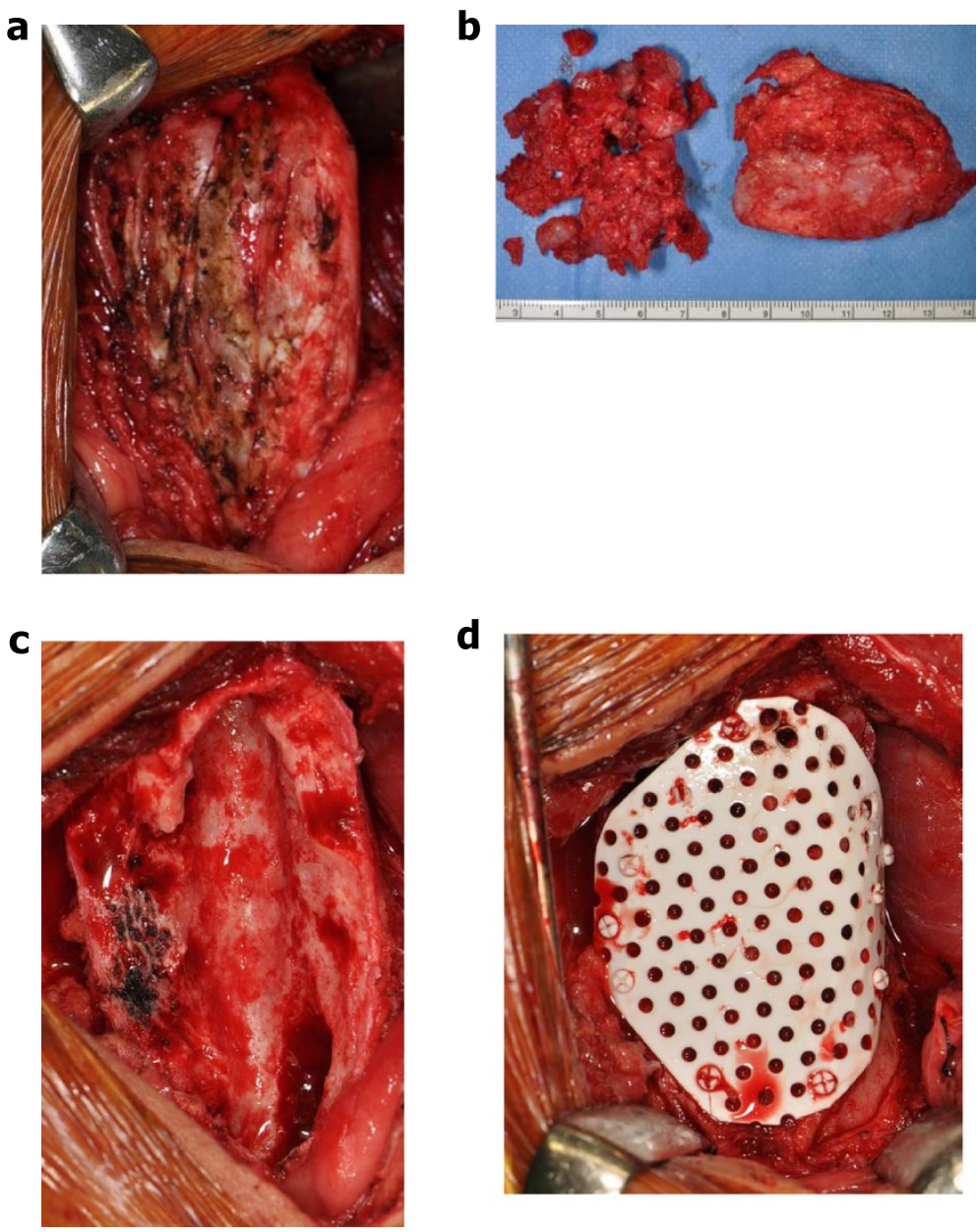

Figure 4 Intraoperative findings. (a) The tumor located on the anterior aspect of the right distal femur. (b) Macroscopic examination of the specimen treated by intralesional resection and intensive curettage. (c) The large bone defect after resection of the tumor. (d) Appearance of the lesion after reconstruction of the defect with IP-CHA and a bioresorbable plate.

a

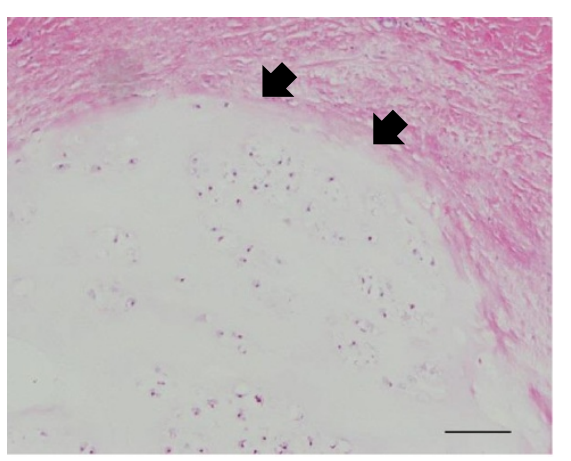

b

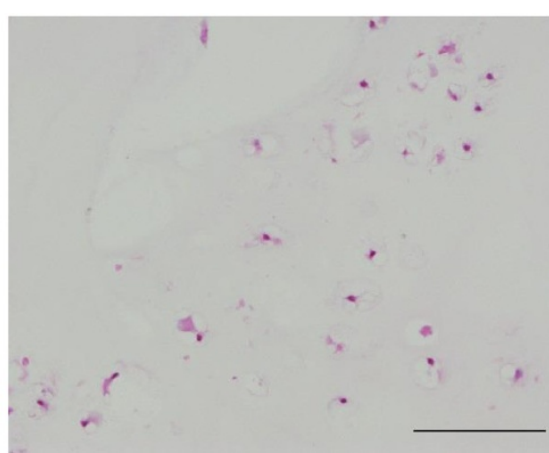

Figure 5 Histology of the resected specimen (H \& E stain). (a) Benign hyaline cartilage tumor covered with periosteum. Arrow heads indicate the border between the lesion and the periosteum. (b) Hypocellular cartilage tumor without cytologic atypia and mitosis. Scale bars: $100 \mu \mathrm{m}$. 
a

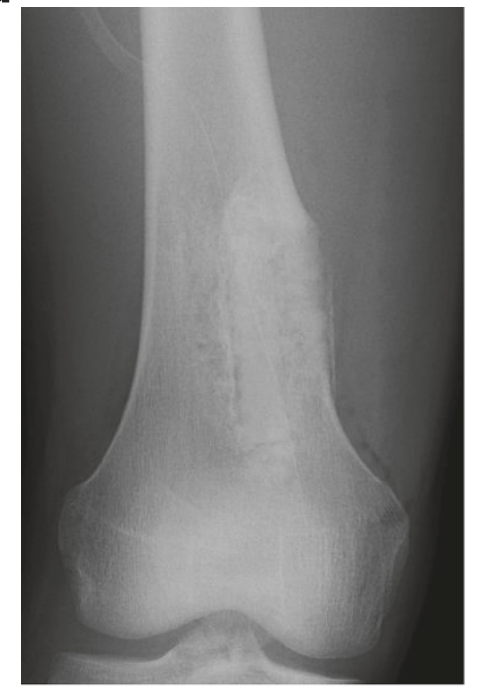

C

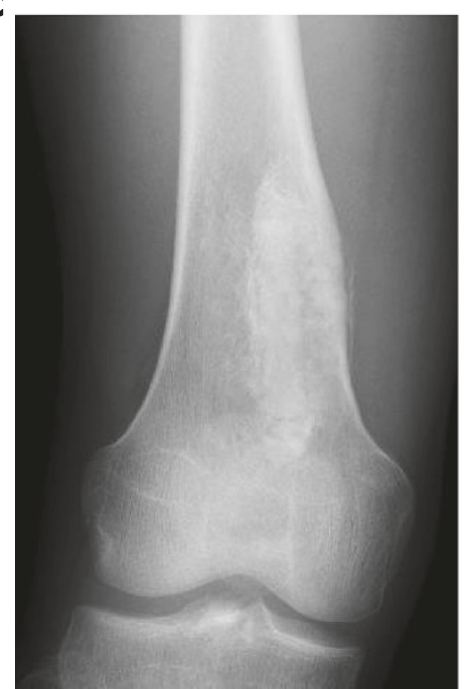

b

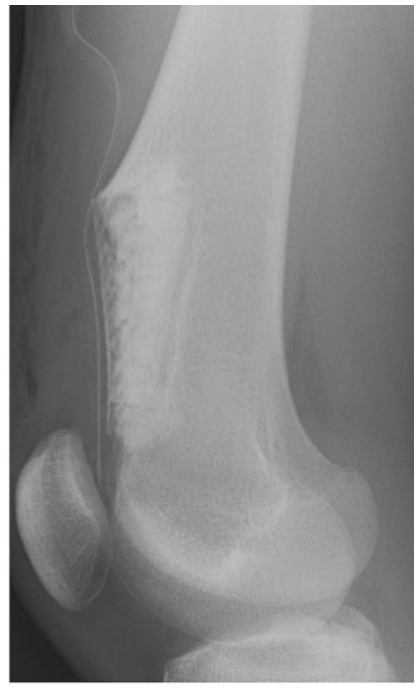

d

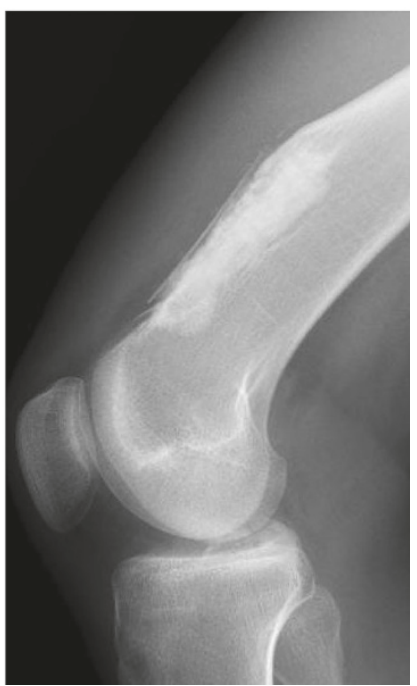

Figure 6 Postoperative plain radiographs. (a) Anteroposterior and (b) lateral postoperative routine radiographs showing the bone defect filled with IP-CHA and covered with a bioresorbable plate. (c) Anteroposterior and (d) lateral radiographs at 12-month follow-up showing no local recurrence of the tumor. Particles of IP-CHA were almost consolidated.

morbidity and functional deficit $[13,14]$. As the potential for local recurrences and metastases in low-grade periosteal chondrosarcomas is extremely low, the necessity of a wide margin is controversial for them [13-20]. Many authors described that less extensive surgery was indicated for low-grade chondrosarcomas, resulting in a good functional outcome [15,19-21]. Conversely, the recommended treatment for periosteal chondroma is intralesional or marginal resection $[4,6]$. According to a literature review of Lewis et al. [4], out of 165 cases of periosteal chondromas, only six cases of local recurrence were reported, a recurrence rate of 3.6\%. Mora et al. [22] demonstrated that the reported cases of local recurrence could be attributed to inadequate intralesional excision. No malignant transformation, metastasis, or multiple lesions have been reported. In the present case, intraoperative rapid pathological diagnosis of periosteal chondroma or lowgrade periosteal chondrosarcoma was made and thus we carried out intralesional resection and intensive curettage to the entire lesion.

A large bone defect occurring after resection of the tumor is frequently problematic. Recently, resorbable bone devices have been developed [23,24]. Super FIXSORB $\mathrm{MX}^{\circ}$ is a bioactive and totally resorbable osteosynthetic bone fixation device [24]. This device is made from composites of unsintered hydroxyapatite particles 
and poly L-lactide, which has been reinforced using a unique compression forging process [24]. This device has a modulus of elasticity close to that of natural cortical bone and retains high strength during the period required for bone healing [24-26]. It also shows optimal degeneration, resorption behavior, and osteoconductivity, thus obviating the need for implant removal [24-27]. In addition, in this case, bone grafting alone was not sufficient to reconstruct the bone defect and so we used a bioresorbable plate to prevent particles of IP-CHA from leaking out of the huge defect. The range of motion in the knee was fully recovered, suggesting that the plate did not cause severe adherence or tightness of the quadriceps femoris.

Bioresorbable bone devices have many potential applications in various clinical fields, such as craniofacial, trauma, and spine surgery [27-29]. It has been reported that seven patients with benign bony tumors of the anterior cranial vault and orbit underwent simultaneous bony excision and reconstruction with alloplastic hard tissue replacement implants [30]. However, to the best of our knowledge, this is the first report of reconstruction of the large bone defect after removal of the periosteal chondroma arising in the long tubular bone using synthetic bone grafts and a bioresorbable plate. This novel reconstruction method should be effective for large bone defects after resection and curettage of common benign bone tumors.

\section{Conclusions}

We present a case of a giant periosteal chondroma in the right distal femur of a 17-year-old boy. We successfully treated the patient by intralesional resection and intensive curettage of the tumor and performed reconstruction of the large bone defect by grafting synthetic bone grafts and using a bioresorbable plate.

\section{Consent}

Written informed consent was obtained from the patient for publication of this case report and any accompanying images. A copy of the written consent is available for review by the editor-in-chief of this journal.

\section{Abbreviations}

CT: computed tomography; H \& E: hematoxylin and eosin; IP-CHA: interconnected porous calcium hydroxyapatite; MRI: magnetic resonance imaging.

\section{Competing interests}

The authors declare that they have no competing interests.

\section{Authors' contributions}

$\mathrm{YI}$ wrote the case report and performed the literature research. $\mathrm{AS}, \mathrm{HO}, \mathrm{KH}$, and NN performed the operation. HT and EM performed the pathological evaluation. AM and HY helped in preparing the manuscript. NN revised the manuscript. All authors read and approved the final manuscript.

\section{Acknowledgements}

We thank the patient for consenting publication of this case report.

\section{Author details}

${ }^{1}$ Department of Orthopaedic Surgery, Osaka University Graduate School of Medicine, 2-2 Yamadaoka, Suita, Osaka 565-0871, Japan. ${ }^{2}$ Department of Pathology, Osaka University Graduate School of Medicine, 2-2 Yamadaoka, Suita, Osaka 565-0871, Japan.

Received: 12 April 2014 Accepted: 6 November 2014

Published: 22 November 2014

\section{References}

1. Lichtenstein L, Hall JE: Periosteal chondroma: a distinctive benign cartilage tumor. J Bone Joint Surg Am 1952, 34:691-697.

2. Brien EW, Mirra JM, Luck JV Jr: Benign and malignant cartilage of bone and joint: their anatomic and theoretical basis with an emphasis on radiology, pathology and clinical biology. II: juxtacortical cartilage tumors. Skeletal Radiol 1999, 28:1-20.

3. Robbin MR, Murphey MD: Benign chondroid neoplasms of bone. Semin Musculoskelet Radiol 2000, 4:45-58.

4. Lewis MM, Kenan S, Yabut SM, Norman A, Steiner G: Periosteal chondroma: a report of ten cases and review of the literature. Clin Orthop Relat Res 1990, 256:185-192.

5. Boriani S, Bacchini P, Bertoni F, Campanacci M: Periosteal chondroma: a review of twenty cases. J Bone Joint Surg Am 1983, 65:205-212.

6. Bauer TW, Dorfman HD, Latham JT Jr: Periosteal chondroma: a clinicopathologic study of 23 cases. Am J Surg Pathol 1982, 6:631-637.

7. Nojima T, Unni KK, Mcleod RA, Pritchard DJ: Periosteal chondroma and periosteal chondrosarcoma. Am J Surg Pathol 1985, 9:666-677.

8. Robinson P, White LM, Sundaram M, Kandel R, Wunder J, McDonald DJ, Janney C, Bell RS: Periosteal chondroid tumors: radiologic evaluation with pathologic correlation. AJR Am J Roentgenol 2001, 177:1183-1188.

9. Tamai N, Myoui A, Tomita T, Nakase T, Tanaka J, Ochi T, Yoshikawa H: Novel hydroxyapatite ceramics with an interconnective porous structure exhibit superior osteoconduction in vivo. J Biomed Mater Res 2002, 59:110-117.

10. DeSantos LA, Spjut HJ: Periosteal chondroma: a radiographic spectrum. Skeletal Radiol 1981, 6:15-20.

11. Woertler K, Blasius S, Brinkschmidt C, Hillmann A, Link TM, Heindel W: Periosteal chondroma: MR characteristics. J Comput Assist Tomogr 2001, 25:425-430.

12. Bertoni F, Boriani S, Laus M, Campanacci M: Periosteal chondrosarcoma and periosteal osteosarcoma: two distinct entities. J Bone Joint Surg Br 1982, 64:370-376.

13. Goedhart LM, Ploegmakers JJ, Kroon HM, Zwartkruis EC, Jutte PC: The presentation, treatment and outcome of periosteal chondrosarcoma in the Netherlands. Bone Joint J 2014, 96-B:823-828.

14. Chaabane S, Bouaziz MC, Drissi C, Abid L, Ladeb MF: Periosteal chondrosarcoma. AJR Am J Roentgenol 2009, 192:W1-W6.

15. Hanna SA, Whittingham-Jones $P$, Sewell MD, Pollock RC, Skinner JA, Saifuddin A, Flanagan A, Cannon SR, Briggs TW: Outcome of intralesional curettage for low-grade chondrosarcoma of long bones. Eur J Surg Oncol 2009, 35:1343-1347.

16. Streitburger A, Ahrens H, Balke M, Buerger H, Winkelmann W, Gosheger G, Hardes J: Grade I chondrosarcoma of bone: the Munster experience. J Cancer Res Clin Oncol 2009, 135:543-550.

17. Hickey M, Farrokhyar F, Deheshi B, Turcotte R, Ghert M: A systematic review and meta-analysis of intralesional versus wide resection for intramedullary grade I chondrosarcoma of extremities. Ann Surg Oncol 2011, 18:1705-1709.

18. Leerapun T, Hugate RR, Inwards CY, Scully SP, Sim FH: Surgical management of conventional grade I chondrosarcoma of long bones. Clin Orthop Relat Res 2007, 463:166-172.

19. Campanacci DA, Scoccianti G, Franchi A, Roselli G, Beltrami G, Ippolito M, Caff G, Frenos F, Capanna R: Surgical treatment of central grade 1 chondrosarcoma of the appendicular skeleton. J Orthop Traumatol 2013, 14:101-107.

20. Aarons C, Potter BK, Adams SC, Pitcher JD Jr, Temple HT: Extended intralesional treatment versus resection of low-grade chondrosarcoma. Clin Orthop Relat Res 2009, 467:2105-2111. 
21. Donati D, Colangeli S, Colangeli M, Di Bella C, Bertoni F: Surgical treatment of grade I central chondrosarcoma. Clin Orthop Relat Res 2010, 468:581-589.

22. Mora R, Guerreschi F, Fedeli A, Alfarano M, Angi V: Two cases of periosteal chondroma. Acta Orthop Scand 1988, 59:723-727.

23. Bergsma JE, de Bruijin WC, Rozema FR, Bos RR, Boering G: Late degradation tissue response to poly (L-lactide) bone plates and screws. Biomaterials 1995, 16:25-31.

24. Shikinami $Y$, Matsuse $Y$, Nakamura $T$ : The complete process of bioresorption and bone replacement using devices made of forged composites of raw hydroxyapatite particles/poly L-lactide (F-U-HA/PLLA). Biomaterials 2005, 26:5542-5551.

25. Verheyen CCPM, de Wijin JR, van Blitterwijk CA, de Groot K: Evaluation of hydroxyapatite/poly (L-lactide) composites: mechanical behavior. J Biomed Mater Res 1992, 26:1227-1296.

26. Yasunaga T, Matsusue Y, Fukukawa T, Shikinami Y, Okuno M, Nakamura T: Bonding behavior of ultrahigh strength unsintered hydroxyapatite particles/poly (L-lactide) composites to surface of tibial cortex in rabbits. J Biomed Mater Res 1999, 47:412-419.

27. Hayashi M, Muramatsu H, Sato M, Tomizuka Y, Inoue M, Yoshimoto S: Surgical treatment of facial fracture by using unsintered hydroxyapatite particles/poly L-lactide composite device (OSTEOTRANS MX ${ }^{\circledR}$ ): a clinical study on 17 cases. J Craniomaxillofac Surg 2013, 41:783-788.

28. Singh V, Kshirsagar R, Halli R, Sane V, Chhabaria G, Ramanojam S, Joshi S, Patankar A: Evaluation of bioresorbable plates in condylar fracture fixation: a case series. Int J Oral Maxillofac Surg 2013, 42:1503-1505.

29. Vaccaro AR, Sahni D, Pahl MA, Harrop JS, Sharan AD, Venger BH, Haid RW Jr, Carrino JA, Vadera S, Hilibrand AS, Alber TJ: Long-term magnetic resonance imaging evaluation of bioresorbable anterior cervical plate resorption following fusion for degenerative and traumatic disk disruption. Spine (Phila Pa 1976) 2006, 31:2091-2094.

30. Eppley BL: Craniofacial reconstruction with computer-generated HTR patient-matched implants: use in primary bony tumor excision. J Craniofac Surg 2002, 13:650-657.

doi:10.1186/1477-7819-12-354

Cite this article as: Imura et al:: A giant periosteal chondroma of the distal femur successfully reconstructed with synthetic bone grafts and a bioresorbable plate: a case report. World Journal of Surgical Oncology 2014 12:354

\section{Submit your next manuscript to BioMed Central and take full advantage of:}

- Convenient online submission

- Thorough peer review

- No space constraints or color figure charges

- Immediate publication on acceptance

- Inclusion in PubMed, CAS, Scopus and Google Scholar

- Research which is freely available for redistribution 